\title{
IDENTIFICATION OF MASS TRANSFER PARAMETERS FOR ROCK SALT DISSOLUTION IN A PLUG FLOW SYSTEM
}

\author{
SZABOLCS FOGARASI ${ }^{a}$, MELINDA NAGY ${ }^{b}$, FLORICA IMRE-LUCACIc, \\ ARPAD IMRE-LUCACla*
}

\begin{abstract}
Considering the particularities of rock salt solution mining, the current paper aims to determine the mass transfer parameters for rock salt dissolution in a plug flow system. The influence of crucial operating parameters such as flow rate and channel depth on the mean driving force, volumetric mass transfer coefficient and extraction yield was evaluated. It was found that flow rate increase intensifies the dissolution process leading to a more rapid dissolution of the rock salt deposit. Similar effect was noticed in the case of flow channel depth increase which leads to higher mass transfer area, increasing the amount of dissolved salt from the rock salt deposit.
\end{abstract}

Keywords: dissolution, mass transfer, salt mining, plug flow

\section{INTRODUCTION}

Romania has one of the largest salt rock deposits in Europe reaching over 43 billion tones and in some situation containing layers of $2 \mathrm{~km}$ thick. The biggest mines are at Gura Slănic (14 mil. t), Ocnele Mari (12 mil. t), Cacica (10 mil. t), Ocna Mureș and Praid (9 mil. t) [1]. There are two main industrial scale techniques applied for rock salt extraction: traditional shaft

a "Babes-Bolyai" University, Faculty of Chemistry and Chemical Engineering, Department of Chemical Engineering, 11 Arany Janos Str., RO-400028, Cluj-Napoca, Romania.

b University of Agriculture Science and Veterinary Medicine, Department of Food Science and Technology, 3-5 Calea Mănăștur Str., RO-400375, Cluj-Napoca, Romania.

c Physico-Chemical Analyses Center, Interdisciplinary Research Institute on Bio-Nano-Sciences, Babeş-Bolyai University, 42 Treboniu Laurian Str., RO-40271, Cluj-Napoca, Romania.

*Corresponding author: aimre@chem.ubbcluj.ro 
mining or via solution mining [2]. An important advantage of solution mining is accounted to the direct production of saturated raw brine which can be used for chlorine and soda ash production as well as for food products and for a wide range of industrial applications [3]. For instance, at Ocnele Mari 1.5 million $\mathrm{m}^{3}$ of concentrated brine $(308-310 \mathrm{~g} / \mathrm{L})$ was produced for a chemical plant, using partially saturated brine $(100-110 \mathrm{~g} / \mathrm{L})$ which was introduced in ten operational dissolution wells and evacuated through two extracting wells [2]. The feasibility of solution mining is sustained by the fact that the operation at Ocnele Mari cashed 1.3 millions $€$ which fully covered the cost of the drillings and pipe system necessary to transport the brine [2]. Also, salt solution mining is applied on large scale in the USA where just in New York state 241 wells produced more than 7 million $\mathrm{m}^{3}$ of brine in 2014 for evaporating and chemical manufacturing [4].

Although it is applied at industrial scale, solution mining deals with several technical issues like roof collapsing, cavity shape control and cavity coalesce, which need to be solved for an efficient and safe operation [5]. As a result, the development of efficient solution mining technologies requires the study and understanding of fundamental aspects of two phase solid-liquid mass transfer which is a key issue in the dissolution and extraction of salt from mineral deposits [6]. Many techniques are used in the literature for the evaluation of mass transfer parameters such as fix and fluidized bed dissolution [7], rotating disc method and plug flow systems [8-10]. In the majority of the situations the dissolution techniques are applied in isothermal and isobaric conditions, mainly at atmospheric pressure and ambient temperature and well defined hydrodynamical conditions [10].

Considering that fixed and fluidized bed reactors are widely used in the industry [11], offering a potential solution for process intensification, they present the most common approaches for the study of mass transfer in solidliquid systems using columns with short or long bed of active particles [12, 13]. It could be also applied for the study of rock salt dissolution by using salt particles with well defined geometries or by implying active particles which consist of spherical or cylindrical cores coated with a thin layer of melted rock salt $[14,15]$.

However, based on the technical particularities of rock salt solution mining encountered at industrial level [1,2], it would be more suitable and realistic to assess the dissolution process using a plug flow system besides other techniques. As a result, the current paper aims to study the rock salt dissolution process and determine the evolution of several mass transfer parameters in time, using different flow rates and cylindrical flow channels drilled in a block of rock salt deposit. 


\section{RESULTS AND DISCUSSIONS}

The following main assumptions were considered in the evaluation of the mass transfer parameters for rock salt dissolution in the defined plug flow system:

- It was considered that during the dissolution process channel diameter varied uniformly along the channel depth, maintaining the initial cylindrical geometry.

- The insoluble impurities present in the rock salt deposit have the same influence on the dissolution process regardless the experimental conditions.

- In comparison to the channels, the cavities formed at the bottom of the cannels have a neglectable impact on the mass transfer parameters.

- All the drilled channels have the same rugosity involving similar hydrodynamic conditions and the same ratio between the real and geometrical surface areas.

Based on the above assumptions, the volumetric mass transfer coefficients were determined from the experimental results using the following equation:

$$
k_{v}=\frac{\Delta m}{\Delta t \cdot \Delta C_{m e d}}
$$

where: $k_{v}$ - mean volumetric mass transfer coefficient for period $\Delta t$, $\left(\mathrm{kg} /\left(\mathrm{kg} \cdot \mathrm{m}^{-3} \cdot \mathrm{s}^{-1}\right) ; \Delta m\right.$ - amount of dissolved rock salt over the period of time $\Delta t$, (kg); $\Delta t$ - dissolution time period, (s) and $\Delta C_{\text {med }}$ - mean driving force, $\left(\mathrm{kg} \cdot \mathrm{m}^{-3}\right)$.

The results indicate (Fig. 1) that the volumetric mass transfer coefficients are increasing in time regardless the applied flow rate or channel depth. This can be accounted to a more rapid increase of mass transfer surface area than the decrease of mass transfer coefficients due to the geometry variations in time.

It was also found, that the difference between the volumetric mass transfer coefficients obtained at the lowest and highest flow rates decrease from $70 \%$ to $18 \%$ with the increase of channel depth from $3 \mathrm{~cm}$ to $5 \mathrm{~cm}$. However, it is obvious that this difference can be accounted to a more significant increase of volumetric mass transfer coefficients at the flow rate of $10 \mathrm{~mL} / \mathrm{min}$ than at $30 \mathrm{~mL} / \mathrm{min}$, which suggests that the dissolution process is more strongly affected by channel depth variations at low flow rates. 

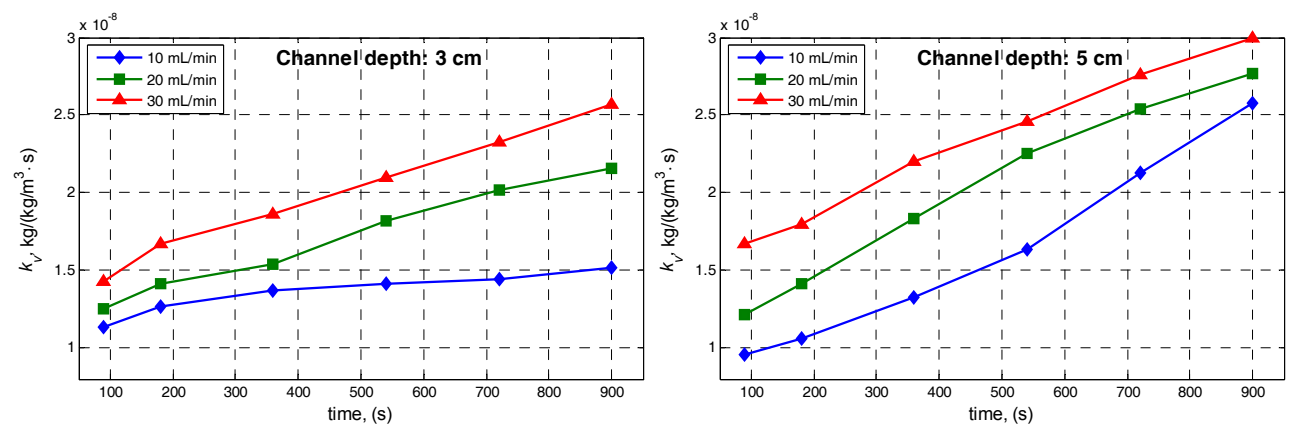

Figure 1. Volumetric mass transfer coefficient vs. time at different channel depths and flow rates.

According to other studies there are two methods for the calculation of the driving force: (i) as the difference between the saturation concentration and the concentration of salt at the exit of the channel or (ii) by the mean driving force defined by eq. (2). The driving force has comparable values for both methods when the salt concentration at the entrance is equal to zero. Still, the driving force for rock salt dissolution was determined by eq. (2), considering that even in this particular situation several studies recommend the use of the mean driving force.

$$
\Delta C_{\text {med }}=\frac{\left(C^{*}-C_{i}\right)-\left(C^{*}-C_{f}\right)}{\ln \frac{C^{*}-C_{i}}{C^{*}-C_{f}}}
$$

where: $\Delta C_{\text {med }}$ - mean driving force $\left(\mathrm{kg} \cdot \mathrm{m}^{-3}\right)$; $C^{*}$ - saturation concentration, (310 $\left.\mathrm{kg} \cdot \mathrm{m}^{-3}\right) ; C_{i}$ - initial concentration, $\left(\mathrm{kg} \cdot \mathrm{m}^{-3}\right)$ and $C_{f}$ - final concentration, $\left(\mathrm{kg} \cdot \mathrm{m}^{-3}\right)$.

Channel geometry variation also leads to the increase of the mass transfer surface area and residence time in the channel which together involve the formation of a more saturated solution in time. As a result, higher concentrations in the effluent involve the decrease of the mean driving force in time for all the experimental conditions.

However, Fig. 2 shows that this tendency is more important at low flow rates which involve higher residence times and higher salt concentrations than at higher flow rates. The results also indicate that the increase of channel depth from $3 \mathrm{~cm}$ to $5 \mathrm{~cm}$ also diminishes the mean driving force which decreased with $10 \%$ at $10 \mathrm{~mL} / \mathrm{min}$ and with only $2 \%$ at $30 \mathrm{~mL} / \mathrm{min}$, being more stable in time at higher flow rates. 

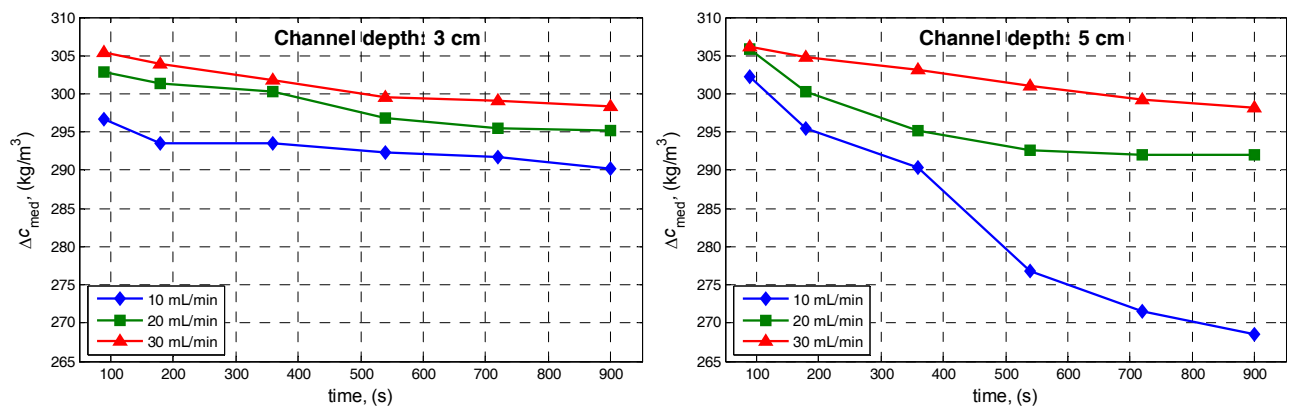

Figure 2. Mean driving force vs. time at different flow rates and initial channel depths.

Another important parameter, the extraction yield $\left(\eta_{i}\right)$ was also evaluated being defined as the ratio between the amount of dissolved rock salt $\left(\Delta m_{i}\right)$ and the amount of rock salt that can be theoretically dissolved $\left(m_{0}\right)$ during the experiment if the obtained solutions would have been saturated.

$$
\eta_{i}=100 \cdot\left(\frac{\Delta m_{i}}{m_{o}}\right)
$$

The extraction yield is a useful parameter because it indicates the operating conditions which allow the extraction of the highest amount of salt with the lowest amount of solvent. According to Fig. 3 the extraction yield increases with the increase of channel depth and with the decrease of flow rate. It can be observed that the geometry variations during the dissolution process also lead to the increase of the extraction yield with time, due to the formation of more saturated solutions. It was found that the extraction yields obtained at the lowest flow rate are 2-3 times higher than the ones obtained at the highest flow rate. Similarly to the volumetric mass transfer coefficient and mean driving force, the extraction yield is affected more strongly by channel depth increase at low flow rates than at higher ones.
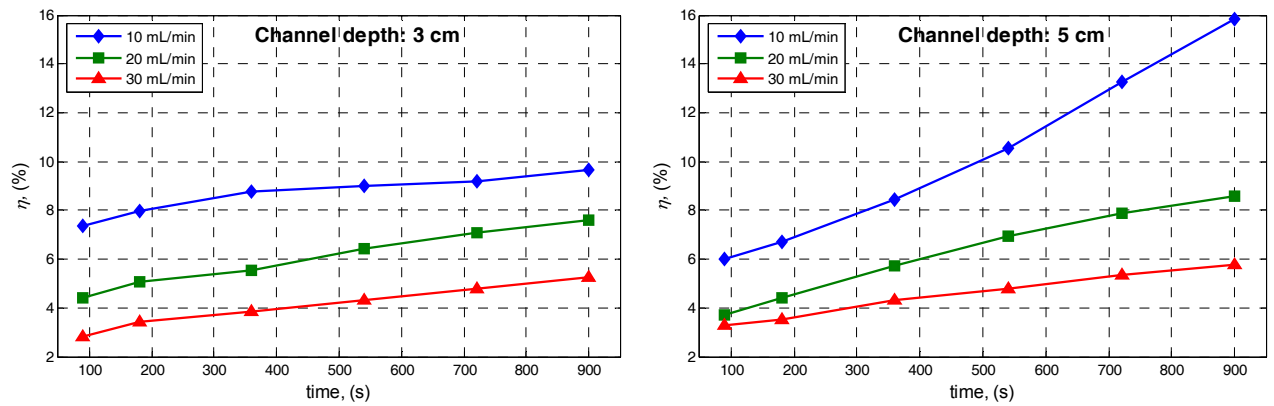

Figure 3. Extraction yield vs. time at different flow rates and initial channel depths. 


\section{CONCLUSIONS}

The current study revealed that rock salt extraction for brine production can be applied efficiently via solution mining by using a continuous plug flow system. Based on the experimental results it can be concluded that process performance is more strongly affected by channel depth variations at low flow rates than at higher ones. As an overall conclusion, it can be stated that the dissolution of rock salt in the studied continues plug flow system occurs the most rapidly at $30 \mathrm{~mL} / \mathrm{min}$ and a channel depth of $5 \mathrm{~cm}$ while the most efficiently at $10 \mathrm{~mL} / \mathrm{min}$ and a channel depth of $5 \mathrm{~cm}$.

\section{EXPERIMENTAL SECTION}

The experimental setup used for the assessment of rock salt extraction performance via solution mining (Fig. 4) included a rock salt block, pump for solvent and solution circulation and reservoirs for solvent and obtained solution storage.

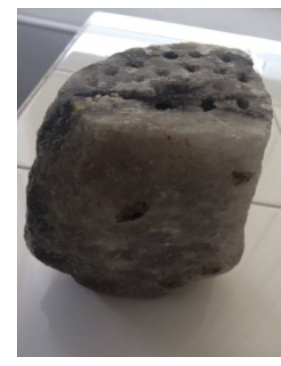

(a)

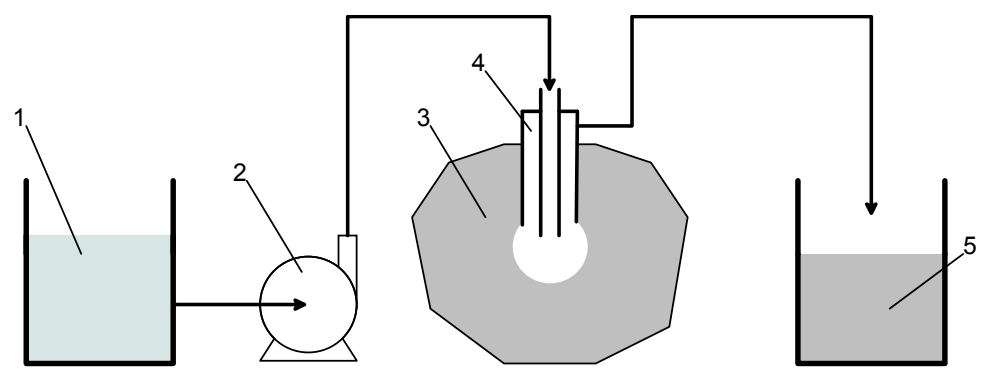

(b)

Figure 4. Rock salt block (a); Experimental setup (b).

1 - fresh water tank; 2 - pump; 3 - rock salt block; 4 - extraction head; 5 - brine tank.

The experimental tests were performed at room temperature and atmospheric pressure using channels with constant diameter of $3.3 \mathrm{~mm}$. The dissolution process with duration of 15 min implied two channel depths of 3 and $5 \mathrm{~cm}$ and solvent flow rates ranging between 10 and $30 \mathrm{~mL} / \mathrm{min}$. In order to determine the mass transfer parameters, the dissolved salt concentration in the obtained brine was quantified for different periods of time at the exit of the channel and in the reservoir as well. Sample concentration, $c$, was determined based on the below calibration curve using refractive index, $n$, measurements (Fig. 5). 


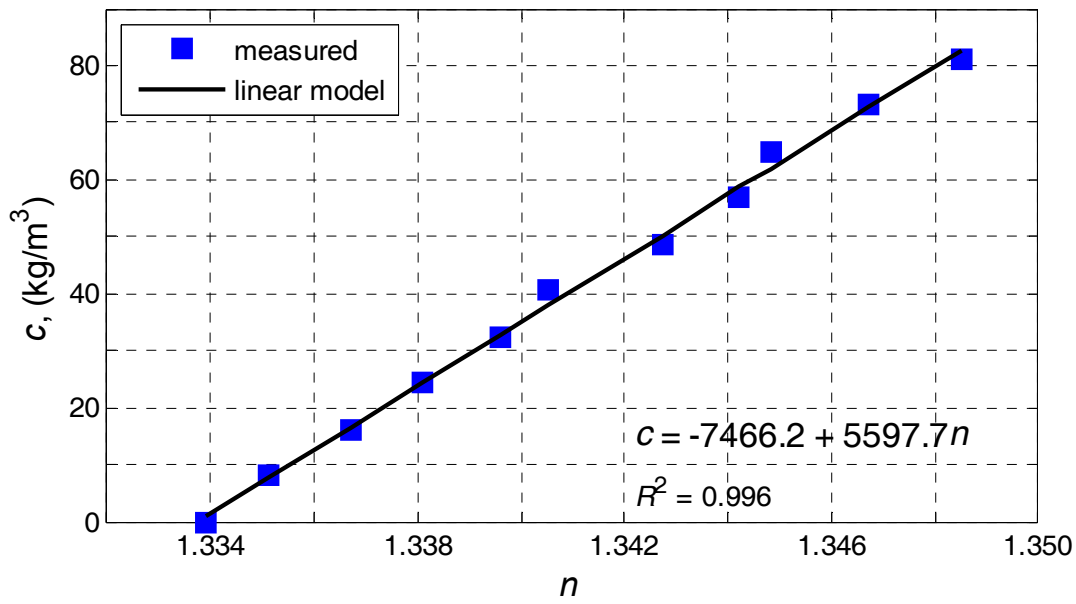

Figure 5. Calibration curve.

\section{REFERENCES}

1. G. Udubasa, S.S. Udubasa, Romanian Journal of Mineralogy, 2008, 83, 27.

2. F. Zamfirescu, N. Giurgiu, V. Popescu, S. Copaescu, Romanian Journal of Mineralogy, 2008, 83, 31.

3. S. Mihuţ, D.P. Marian, E. Cozma, I. Onica, International Multidisciplinary Scientific GeoConference Surveying Geology and Mining Ecology Management, SGEM, 2015, 3, 543.

4. J.D. Johnson, J.R. Graney, R.C. Capo, B.W. Stewart, Appl Geochem, 2015, 60, 37.

5. T.E. Tomastik, Carbonate Evaporite, 1997, 12, 2, 236.

6. S. Dragan, Studia UBB Chemia, 2016, LXI, 3, Tom I, 227.

7. S. Fogarasi, F. Imre-Lucaci, S. Dragan, A. Imre-Lucaci, Studia UBB Chemia, 2016, LXI, 3, Tom II, 495.

8. M.H. Abdel-Aziz, M. Bassyouni, I.A.S. Mansour, A. Nagi, J Ind Eng Chem, 2014, 20, 5, 2650.

9. L. Zeng, Y. Zhang, Q. Liu, L. Yang, J. Xiao, X. Liu, Y. Yang, Chem Eng J, 2016, 289, 452.

10. S. Petrescu, I. Fechete, C. Ciubotariu, Chem Eng J, 1998, 69, 39.

11. I. Mohammed, T. Bauer, M. Schubert, R. Lange, Chem Eng Sci, 2014, 108, 223.

12. S. Drăgan, Studia UBB Chemia, 2015, 60, 3, 183. 
SZABOLCS FOGARASI, MELINDA NAGY, FLORICA IMRE-LUCACI, ARPAD IMRE-LUCACI

13. S. Drăgan, Studia UBB Chemia, 2013, 58, 4, 53.

14. R.V. Garić-Grulović, Ž.B. Grbavčić, N. Bošković-Vragolović, Z.L. Arsenijević, Powder Technol, 2009, 189, 1, 130.

15. L.A. Calcada, L.A.A. Martins, C.M. Scheid, S.C. Magalhães, A.L. Martins, J Petrol Sci Eng, 2015, 126, 97. 